Branislav Spasic ${ }^{1}$, Aleksandar Markovic ${ }^{2}$

${ }^{1}$ Organization for Security and Co-operation in Europe, Serbia

${ }^{2}$ University of Belgrade, Faculty of Organizational Sciences

\title{
Information and Communication Technology Unit Service Management in a Non-profit Organization Using ITIL Standards
}

UDK: 007:005]:004; 005:061.2

DOI: 10.7595/management.fon.2013.0005

The study subject of this paper is the use of management standards and recommendations in the implementation of ITIL standards and best practices in the management of Information and Communication Technology unit. The conceptual implementation model consists of analysis, observations and implementation of best practices and methodologies in order to develop an integrated system compatible with the needs of an international non-profit organization. The paper elaborates the key aspects of corporate culture combined with the rules and regulations in order to maximize the quality of service, its efficiency and availability. One of the most important services is the management of client support in order to maximize the efficiency of service delivered to clients. This paper also illustrates the practical implementation of the ITIL best practices within the Organization for Security and Co-operation in Europe (OSCE), the Office for Democratic Institutions and Human Rights, using software tools and documented procedures to manage services, infrastructure and resources.

Keywords: Information Technology Management, ITIL, Service Support, Information Technology Services.

\section{Introduction}

The topic of this paper is the use of management standards and recommendations in the management of the information and communications technology unit using the ITIL ${ }^{1}$ standards and the best practice. The conceptual model of implementation comprises the analysis, discussion and implementation of the best practice and methodology in order to developan integrated system, suitable to an international non-profit organization. The paper discusses the key aspects of corporate culture and service rules for the purpose of providing the maximum quality of service, efficiency and availability of the service. The aim of this paper is to offer an insight into the ITIL framework and explain the basic principles ruling the ICT service management.

In dynamic and dramatic changes in business environmentorganizations are exposed to risk. One way for the companies to overcome the problems, induce change and attain the promptness and accuracy in decision-making is the information and communications technology management. The information technologies evidently are the central neural system of any organization; accordingly, their role becomes only more significant. An efficient management of technology and services as well as of the facilities it offers ensures a substantial advantage and control over one's business operations.

One definition in the ITSM ${ }^{2}$ publication describes service as a means of delivering value to customers by facilitating outcomes customers want to achieve without the ownership of specific costs and risks. (Cartlidge, Alison; Ashley, Hanna; Rudd, Colin; Macfarlane, Ivor; Windebank, John; Rance, Stuart:, 2007).

${ }^{1}$ ITIL - Information Technology Infrastructure Library

2ITSM - Information Technology Service Management 
The two basic goals set before the organizations that embark on the development of the ITIL solutions in IT service management are the following: improvement of IT service management and thus raising the organizational effectiveness and performance and, simultaneously, increasing the effectiveness in achieving business goals while reducing the overall costs to the measure that they do not make an adverse effect upon the quality of output product or service delivery.

The basic task of the ITIL is primarily directed to the alignment of the IT system with the needs of the company. Hence, the ITIL is not designed to deal with technicalities, that is, it does not provide an answer to the question on which technological solution should be used to achieve a certain outcome, but rather to that of what should be achieved. It is the task of the organization to implement an adequate technical solution. It is also independent of the organizational structure, the IT system architecture or the technologies applied, it ensures a uniform terminology in IT processes management and provides a reliable insight into the concrete processes in the organization.

An overall acceptability and prevalence of the ITIL framework implementation is affected by three factors. The first factor is that ITIL methodology is available to everybody and this framework is kept updated by the government, that is, non-profit organizations. The second factor of the ITIL success is the adoption of this standard by the major global organizations. The last, third, and perhaps the most important factor is the availability of a large amount of specialised literature and material (web-sites and books) that can help respond to the challenges the ITIL sets before its users.

\subsection{ITIL background and standards}

The ITIL framework historical perspective was conditioned by the development of information technologies. The development of the IT service management evolved gradually as the development of services supported by the developing technologies developed.

In its early phase, information technologies were mainly focused upon the development of applications and ended there. An improvement of this evident benefit gained through this technology meant focusing upon the delivery of new applications as part of a larger service offer that supported business operations as such.

During the 1980s service management was more broadly implemented, and business became increasingly dependent on its use. As meeting the business needs required a more radical focus upon the IT service approach, the "Technical support" was faced with ever more frequent problems and so were all the others who tried to use IT services in delivering their own services. It was at that time that the British government who strived to efficiency in the business of the IT sectors of its agencies commenced the creation of documents that would describe the methods by which the most successful organizations tackled the issue of service management. By the end of the 1980s and in the early 1990s they had already published a series of books that document the approach of the IT service management meant for the business users support. Following the initial editions that marked the period from 1989 till 1996, the number of books that made up the version $1 \mathrm{ITIL}^{3}$ promptly rose to over 30 volumes.

The genesis of the IT framework started towards the end of the 1980s when the British government came to a conclusion that the quality of IT services of some government agencies was below a satisfactory level and also far from uniform. The task to structure, standardize and unify the IT systems of all the government agencies was commissioned to the CCTA4. In April 2001 the CCTA was assimilated by the OGC 5 , the HM Treasury Office(Office of Government Commerce (UK)CCTA and OGC, 2005)

In 2006, the ITIL Glossary, version 2, was published, and in May 2007 this organization issues the third version $^{6}$ which comprises 26 processes and functions arranged on the bases of the service life cycle structure

\footnotetext{
${ }^{3}$ ITIL V1 ITIL

${ }^{4}$ CCTA-Central Computer and Telecommunications Agency

${ }^{5} \mathrm{OGC}$ - Office of Governmental Commerce

${ }^{6}$ ITILV3
} 
organized in 5 volumes, as follows: Service Strategy, Service Design, Service Transition, Service Operation and Continual Service Improvement. In July 2011 Edition 2001 was issued, so far the latest updated version of the 2007 document.

Given that the IT and business systems of various organizations do not exist in a vacuum but develop over time, this development has to be followed by the ITIL framework too. It is important to note that, in addition to the best ITIL practice and solutions, there are also certification levels of the knowledge for physical persons as well as for companies.

There are three basic levels in the ITIL system of certification for physical persons. The first, the ITIL Foundation Certificate ${ }^{7}$, is a statement that a person has a basic knowledge of the ITIL concepts and processes and that this person is well acquainted with the fundamental nature of the ITIL standards. The fundamental level is an imperative for attaining the other two ITIL certificates. The second, the ITIL Intermediate Certificate $^{8}$, proves that the person has mastered the knowledge required to implement the ITIL framework within a certain organization. The third, the ITIL Advanced Level Certificate ${ }^{9}$, is for the ITIL experts with a long experience and numerous completed projects.

An organization cannot be certified on this basis; to prove to its partners that it has successfully introduced the ITIL standard into its business operation, there is the ISO/IEK 20000 certificate.

\subsubsection{ISO 20000 Standard - IT service management}

ISO/IEC 20000 is the first international standard in IT service management. The standard combines all the aspects of IT service management that can be implemented in all IT organizations.

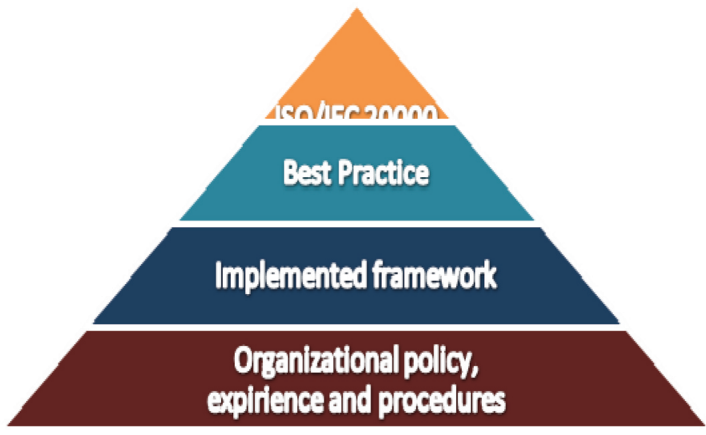

Figure 1. 20000 Standard within ITIL framework

The ISO/IEK 20000 standard followed the BS 15000 standard and is a legitimate successor of the latter. The BS 15000 standard is the world's first standard in IT service management. The standard specifies a set of interrelated management processes, and is based heavily upon the ITIL (IT Infrastructure Library) framework. The BS 15000 standard was transformed into the ISO/IEC 20000 and published in 2005. With respect to the growing market needs and requirements for a formal certification the $\mathrm{BSI}^{10}$ issued the $\mathrm{BS} 15000$ 1:2002 and BS 15000-2:2003 standards. These standards were adopted by the markets; however, a broader implementation is conditioned by the requirements for internationalization.

These two standards were adopted under a speedy procedure and published in 2005, as ISO 20000-1 and ISO 20000-2:2005 standards.

${ }^{7}$ ITIL Foundation Certificate

${ }^{8}$ ITIL Intermediate Certificate

9 ITIL Advanced Level Certificate

${ }^{10} \mathrm{BSI}$ - British Standards Institution. The British Standard Institution is a multinational institution established in 1901 and dealing in service

delivery. The core activity is the formulation of standards and provision of standard-related services. 
In 2011, the ISO 20000-1 standard was replaced by the new standard of the same title. It is process oriented both in structure and in contents, completely compatible with the ISO 9001:2000 and includes the specification of requirements for the system of IT service management.

The second section of the ISO/IEC 20000-2:2012 standard contains a specification of the best practice in the IT service delivery on a high level, independent of the available technical solutions, and is entirely founded on the requirements based on the ISO/IEC 20000-1:2011 ITIL.(Lisse \& Lisse, 2006)

The third section of the ISO/IEC ${ }^{11} 20000-3: 2009$ gives guidelines on the definition of the competence, applicability and presentation of alignment for the service deliverers who plan to improve services and to use the ISO/IEC 20000 as a business goal. This section of the standard complements the advice within the ISO/IEC 20000-2 as regards the generic guidelines for the implementation of the service management system in accordance with the ISO/IEC 20000-1.

The fourth section of the standard, ISO/IEC TR 20000-4:2010, is meant to facilitate the development of a process assessment model, in accordance with the ISO/IEC 20000-1 process assessment principles.

The ISO/IEC TR 20000-5:2010 is a plan of implementation of examples providing guidelines to the service suppliers as to how they should implement the service management system in order that they satisfy the requirements of the ISO/IEC 20000 standard as their business goal. Similarly, this standard can be of use to those who councel the service providers as to how the latter can best meet the requirements of the ISO/IEC 20000-1 standard. The ISO/IEC 20000 standard, as its predecessor, the BS 15000 was primarily developed to present the guidelines for the best practice contained in the ITIL framework, although it also supports and accesses other IT service management frameworks, such as Microsoft Operations Framework and the components of ISACA ${ }^{12} \mathrm{COBIT}^{13}$ frameworks.

\section{ITIL as framework for IT service management}

In the corporate world today it does not suffice to manage the information and communication services at low costs. Year by year, there are requirements for an ever less expensive and ever higher quality management, a long-term stability of practice, a high standard reporting, flexibility and a reduced reliance on individuals.

A reference model titled ITSM is also an entirely integrated map of information technologies on a highest level. Its implementation has proven that it is of paramount value for the companies worldwide that strive to apprehend their problems related to people, processes and technology and then consider possible solutions.. (Bečejski-Vujaklija, 2007)

One solution, provided by the use of the best practice library, lies in the simplicity, correct definition and documentation of the IT service catalogue, as well as in the structured introducing of a succession of service management processes.

The implementation of the ITIL methods proposes the processes, functions, certain software tools and techniques for a more efficient support to services. The use of the ITIL framework is based on the eclectic approach in the form of recommendations, rather than in the form of orders or one-direction instructions. The ITIL framework theory is rather extensive and requires a systematic approach, while a path to a good implementation means a several-year lasting efforts with any number of challenges. Solutions may be either very expensive or non-expensive, based on an open code. Teams of IT experts may adopt a model relatively easily, however, they may find the changes of additional process administration difficult to cope with.

\footnotetext{
${ }^{11}$ TR - Technical Report.Approved technical report. The technical report is developed as a standard; however, its purpose is to supply technical information, not to require the satisfying of certain requirements in implementation.

${ }^{12}$ ISACA - The Information Systems Audit and Control Association is a professional association responsible for IT management.

${ }^{13}$ COBIT - Control Objectives for Information and Related Technologies is a framework of Control Objectives for Information and Related Technologies. It was established by the ISACA. It supports a set of tools via which managers can bridge the gap among the requirements for control, the technical issues and the business risks.
} 
The problems in introducing may differ, regardless of the scope and nature of business. Very often the software solutions are taken for granted and this may result in an increased number of problems and a longer implementation period. It is for this reason that the automation of processes in services cannot be fully accomplished due to the very nature of services ${ }^{14}$.

The reality is that practice does not know business that implemented all the recommended processes and tools. It is, however, clear that the ITIL framework is highly helpful in conducting and managing the IT operations and that there are numerous companies that achieve their competitive advantage through perfect operations based on this method. A real proof of an adequate implementation of solutions, in the context of evidence that the organization has consistently and successfully introduced the ITIL standards into its business operations, is the ISO/IEC 20000 certificate. A close connection between the 20000 standard and the ITIL is related to the very beginnings of the information technologies management in the development of which many organizations did participate.

The development of the ISO/IEC standard is continual and absolutely compatible with the ISO/IEC 9001 standard and includes the specification of requirements for the IT service management system.

Because of the link between costs and efficiency of support services implementing best practice, service management can drive down the cost of support and therefore the total cost of ownership. Best practices also lead to better service levels, customer retention and lower business risk. ISO/IEC 20000 is also the basis for certification audits and assessments of how well ITIL $®$ advice has been adopted. (Dugmore, Dr Jenny, 2009)

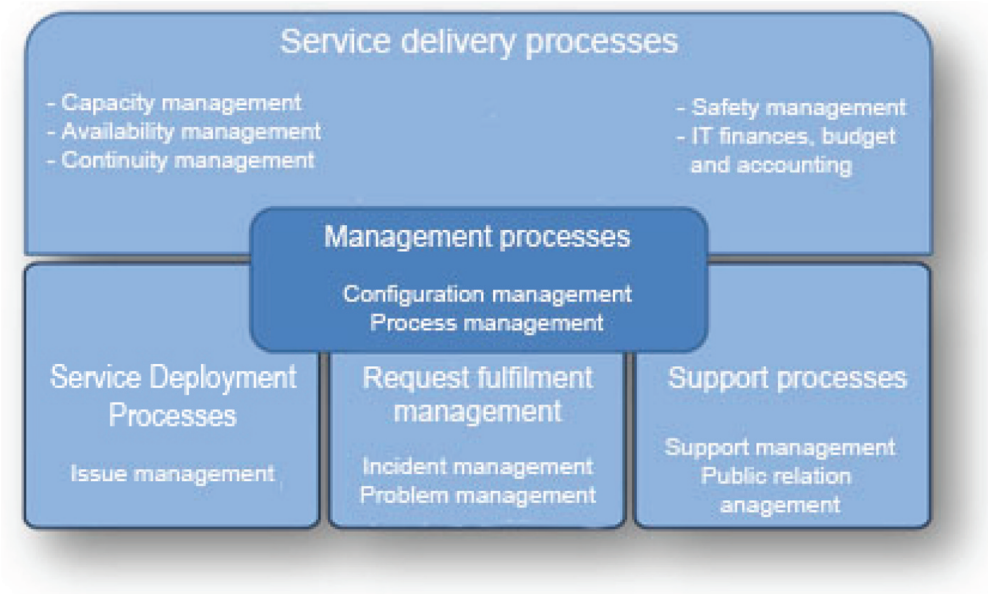

Figure 2. Service management processes, ISO 20000, source (International Organization for Standardization)

The appearance of standards led to the opportunity of certification for IT service management and the goal is perceived in the provision of general recommendations for IT organizations that deliver internal or external services to the users. The ultimate goal of the ISO/IEC 20000 is to:

- Reduce operational exposure to risk,

- Satisfy contracted requirements,

- Demonstrate service quality. (Mr Aleksandar Vujović, 2007)

These management processes give companies a sound basis for meeting the business needs of the users with a defined level of resources. In other words, the service delivered is professional, less expensive and accompanied with a reasonable risk that can be managed.

\footnotetext{
14 "Semi-Automated, not Fully Automated": Prof. Dr W. Edward Deming advocated semi-automation supported by people, one that allows people to change semi-automated or computer-supported knowledge-based processes.
} 
The ISO/IEC 20000 standard helps the organization apprehend and improve the level of IT services and the demonstration of organizational capability of satisfying all the necessary requirements of the users. The concrete benefits the implementation of this standard can yield are: (Portal Kvalitet, 2012)

- alignment of IT services with business goals,

- creating a framework for service quality improvement,

- comparison with the best players in the field of IT services,

- risk and IT service cost reduction,

- creation of a necessary hierarchy and culture within the same organization,

- achieving competitive advantage through promoting steady and profitable services,

- creating a steady framework that fosters automation in service management.

\subsection{Information technology service management concepts}

The information technology service management appears as a concept that is a condensed idea of the ITIL framework. The essential idea is that the ITIL framework extends further than just a conventional sale of goods and services to the customers.

The IT service providers and users are individuals and groups that define and agree on the goals of the service level. The goal of service level refers to the obligation of collaboration between two subjects documented by the service provider to the user, in the form of a service level agreement ${ }^{15}$. In an organization, say, a non-profit one, the service user is specified as the end user, or simply the user.

Contrary to the services related to the sales of a product, where the full cycle of the product refers to its manufacture, distribution and sales, IT services are characterised by an entirely new approach where the delivery of services is effected through different aspects of interaction between the service suppliers and the service users. In this case, the IT service user means primarily the client in a certain company (it can also be a user or a client in our company) who needs informational technology resources or services.

When talking about the information technology services, we usually have in mind yet another service related concept - the service resources. Service resources are defined as opportunities or resources that a service provider offers to his users. When talking about resources, we generally have in mind the resources in the company's ownership, such as, for example, computers, servers, network flow, monitoring services, reporting services, safety services, development of applications, product management, programme management, intellectual property and a host of other services that go far beyond the pure support to a product.

Similarly, the approach to the quality of service is not the same as the approach to the product. Service quality depends on the manner of interaction, information sharing, communication and meeting the business goals between service suppliers and the end users of these services. In case of services, in comparison with the manufacturing of a product, the service provider and the user can correct or change processes, all in the course of, and without interrupting, the service provision.

The following service related concept are service resources. Service resources are any competences or resources of the service provider that can be physically or logically linked to human resources. Service providers can be internal or outsourced ${ }^{16}$. Obviously, if a bidder has services and service resources, he needs to manage these services and resources either autonomously or by outsourcing an external company. This is the point where service management plays its role, the role of support to the business and the profit making business activities. In case of a non-profit organization, however, as is the case that will be presented in this paper, service management will deal with achieving the goals stipulated in the mission and organizational goal statement.

\footnotetext{
${ }^{15}$ Service Level Agreement, SLA

${ }^{16}$ Outsourced, external service providers
} 
Some activities through which the IT service management supports the organization in achieving its goals and its mission statement are the following:

- data storing, data sorting, "data mining",

- data availability,

- facilitating communication,

- services of computer networks, both wired and wireless,

- accelerating business activities,

- provision of productivity increasing tools,

- improving the accuracy of repetitive functions,

- improving the consistency of repetitive activities.

In reality, IT service management makes it possible to find creative solutions that support generating profits for profit-oriented organizations, or meeting organizational goals of non-profit organizations in more effective and more efficient ways, all on a daily basis. These are the key aspects closely linked with business needs and goals that should be effectively managed. The most important moment in service delivery is making impression on customers. These are expectations and requirements that are closely connected with service management and that the service provider is obligated to meet. In case of services, the most important thing is whether the services the provider offers will meet the expectations of the users of these services, that is, whether service users can believe that the level of the service will remain the same, each time they require the service.

The question on services most frequently asked by the users is whether the service will be delivered in the same manner, of the same quality and at a reasonable price each time they request it. Here, management is indispensable, primarily in giving answers to these questions and then in delivering the outcomes the service provider has promised to the users. The Service Level Agreement ${ }^{17}$ serves to ensure the IT service delivery, i.e., to ensure that the service design serves the purpose of meeting the set requirements and is made to the customers' satisfaction.

\section{Case Study - ODHIR, Office for Democratic Institutions and Human Rights, ITIL}

A business case study of the Office for Democratic Institutions and Human Rights (ODHIR) deals with the method of IT service management using the ITIL framework. Special attention is paid to the speed and quality of the service, as well as to the service availability. The study reveals that the commitment of the top and operations management to success, as well as the support and response of the employed in the ICT unit of the company is of decisive importance for the project success. It also reveals that a need is recognized for appropriate changes in the management strategy and the effect of the ICT transformation upon the organizational culture of the Common Services Department ${ }^{18}$ of both the Office and the entire organization.

\subsubsection{Information and Communication Technology Department}

The Information and Communication Technology Department (ICT) is engaged in managing the ICT structure and the delivery of services to around 200 full time employees, as well as to more than 700 geographically dispersed employees in certain time periods during the year. The number of employees rises abruptly in the time intervals where support is provided to the observation missions at the elections held in all the member states as well as in the countries where the ODIHR Office is granted a mandate of an observation mission.

The Information and Communication Technology Department consists of 6 permanent members integrated in a team, with clear tasks and assignments to meet the dynamics of periodical growth and pressure upon the user services. The organizational structure of the ICT department is adjusted to the model of a single point of contact, i.e., a single telephone number and a single e-mail address.

\footnotetext{
${ }^{17}$ Service Level Agreement

${ }^{18}$ Common Services Department
} 
The IT business system consists of: operations systems, local and Internet connections, computer networks safety, technical support, the ERP system, business applications, VolP system, systems of monitoring and physical control of the facilities, web applications, the intranet system, the Internet web site of the organization ${ }^{19}$, electronic mail server, database server, collaboration server, etc.

The ODIHR, ICT department is engaged in designing the budget and costs of the future business ventures, in developing and updating of the ICT operative policy and strategy, in the maintenance of the network infrastructure, in hardware and software, in the user support, in capacity planning and management, in preparing reports for the top management and other departments, and with other activities.

\subsubsection{Challenges with business culture}

The IT service management is a simple concept of service provision to the end users within and outside the corporate infrastructure. The desire to implement the IT services concept that would integrate all the aspects and requirements of the organization hence results in a conclusion that it is necessary to adopt components that would suit the business culture of the organization.

The delivery of the basic IT services, such as incident and problem management, to end users can be rather complex in case of a transition to a "new" management system and questions as to the changes of business habits and, accordingly, the behavioural culture of everybody in the organization.

Similarly to others, the professionals in the ICT unit have an established manner of work and introducing new processes and procedures, regardless of how necessary they are, brings forth changes and disrupts the order of the already routine habits. For this reason, it is important that attention should be paid to human resources and personnel experts be consulted prior to transition to the new model of service delivery.

Speaking on the basis of experience, the implementation of an ITIL business solution within an existing IT service system may condition that a certain percentage of staff be absolutely unprepared to adopt change and that some even resist change. As regards the new framework of IT service management, it should be remembered that in the past, the appearance of many a framework, among them "Balanced Scorecard", Six Sigma, COBIT, the Microsoft framework, and the versions of several ISO and many other standards, subjected IT to any kinds of tastes and quality of these frameworks. The stress put at the beginning of implementation of the ITIL V3 sounded similar to all the above listed frameworks, although experience says that human resources are most important when it comes to the ITIL implementation. The ability to change deeply rooted methods of business doing is the greatest threat to the success in the implementation of the solutions. "The biggest challenge is change the culture," says Jeannette Cook, service level manager at theldaho National Laboratory, of the Ministry of Energetics. She also says that "people have deeply established manners of doing things, so there is fear of new processes".

"One of the goals is the transition of our IT department from internally technologically centralized to externally client-oriented“, says Jeannette Cook.

The employees who are used to their old ways of accomplishing certain tasks and were successful in this work and who are now obliged to learn to do the same work in a new way, most often feel as if they lost control over their environment.

\subsubsection{Short-term Problems with ITIL implementation}

In addition to the anticipated resistance from some people, a number of questions concerning ITIL in requirements management put in the Warsaw ODIHR Office were interesting and were taken into consideration. In any case, the commitment and work of the employed on the project implementation was of great importance for the idea and vision of the project to be implemented.

${ }^{19} \mathrm{http}: / /$ www.odihr.pl 
We will proceed to present the impressions of the managers of prominent world companies that were faced with a certain amount of scepticism in some situations, are related to every implementation of ITIL solution and are also tied with the implementation of the solution that will be discussed in this paper.

The deputy of the marketing president of the Opsver Inc. Company, the service provider for the data canter automation of Sunnyvale, California, says that there is an important, however, often an unfortunate oversight of the aspects of a certain number of ITIL implementations. In many cases the ITIL solution results in case of the employees in the data centre being less efficient, since the ITIL solution insists that standard steps and stipulated procedures should be followed. Experienced system administrators can complete all these same tasks in the same way as with the ITIL, but in a smaller number of steps. It is in such situations that scepticism and real resistance can be expected from the employees.

In the Allstate Insurance Corporation situated in Northbrook, Illinois, some issues of the ITIL process proved to be less efficient. "People understood the need for the implementation of various ITIL processes", says Pet Corrigan, the company's infrastructure deputy president assistant. At the beginning of 2004 and with change management, Allstate implemented ITIL processes within their three data centres, driven by the idea of doing business in this way. "In some situations, certain processes took more time. For example, in the change processes, administrators must also have documentation on the implemented changes, something that requires more effort than before the implementation of the ITIL solution", says Pet Corrigan. Regardless of additional work, the efforts pay. The benefits from the ITIL solutions implementation, especially in view of service management, are worth additional efforts. While, on one hand, the formal processes do require more work at the "front-end", on the other hand, the number of incidents fell. In any case, the end users receive a more reliable service, while on the other hand, the employees in the data centre have "less fire to put out". The manager Pet Corrigan noticed a dilemma in a large number of IT workers who often think that the idea to present something that demands more work and results with less efficiency is not acceptable.

Most important in view of the short-term problem issues is that those employees are to be identified in the change process who are passionate about the process and that they should be given training in the field of service management. They belong to different business groups and are employed as problem managers who help reduce the number of incidents.

In case of the ODIHR implementation it is necessary that the idea should be promoted among all the relevant participants and those mechanisms should be provided to motivate the staff and the management of the company.

\subsubsection{Requirements for service alignment and reasons for ITIL solutions implementation}

Following the decision on launching the implementation it was necessary to define the basic business requirements for the implementation of a good ITIL solution. Prior to launching the implementation of the new solution for ICT services an analysis was conducted of the old system of management and a large number of meetings was held where the following conclusions were reached:

- The old system, "Virtual Support Office" does not meet the conditions for IT service management.

- The access to the system database does not have an adequate system of access and authentication.

- There is no integrated approach to incident and problem solving.

- Reporting and analytic tools are poor or inadequate.

- There is no possibility for integration with other systems.

- Service transition management is not clearly defined.

- Transition is often scheduled and performed in times not specified for this job.

- There is no risk assessment for service transitions.

- There is no possibility for incident management, delegation and escalation.

- Process automation is rather poorly devised.

- Preventive task management does not exist, and there are still more flaws. 
Following a series of interviews and meetings with the top management the ITIL project was approved of. The project was devised as an implementation of the best practice in order to meet the following requirements:

- Alignment of user support services in terms of a prompt response to requests and quality of solutions after the ITIL standards.

- Higher accessibility, availability of services and improved customer satisfaction.

- A single point of contact.

- Improved efficiency and effectiveness of service management.

- Quick alignment of the "state" of the ICT support organizational unit.

- Reduced time spent in search for solutions to frequent repetitive requests through establishment of standard operating procedures.

- IT hardware management (equipment, laptops, computers, etc.).

- Software management (number of licences, their location, updating).

- Prevention tasks to accelerate the processes of issuing, updating and tracking the equipment, processes of software and operation systems updating management, etc.

The project included three phases. The first phase was the phase of preparation and training of employees for their further inclusion into the project. The second phase ran simultaneously with the first one and included an analysis of software tools on the market, the selection of an adequate software solution, as well as numerous analyses, tests and possibilities for implementation. The third phase entailed the employment of software tools and then their configuration and documentation.

In the first phase meetings were held in the form of preparations for the period to come and financial means required for the training of the entire IT unit were planned. Training was necessary for the purpose of including all the employees in the ICT unit into the implementation process and raising awareness of the new method of service management. Special attention was paid to the implementation time, the resources and the costs.

\subsubsection{Analysis of software tools on the market and selection of solutions to request management}

\subsubsection{State of the art at the beginning of the project}

The selection of software tools for ICT service management was conditioned by the requirement that would meet the stipulated criteria (functionality) (Table 2). The previous method of management was based on the control of the incoming requests to the mail box at the ODIHR IT account and used to register electronic requests in the form of e-mail text messages sent by the user. In case requests arrived via a telephone call or direct to the account, they were not registered, which was the major flaw. In other words, such a situation resulted in the lack of visibility of a large number of activities related to technical support and, consequently, a major lack of information that would otherwise allow for an effective planning of activities, user support, solutions to requests and problems, changes and other activities. Similarly, reporting was either not available or it was rather scanty if it was conveyed orally, where most information was lost and the incident and problem solving procedure could hardly be tracked.

The IT manager of the ODIHR Office, together with the ICT department assistants, decided to analyse the software market and find an adequate software tool that would improve the user support activity as well as efficiency, improve the visibility and the control of the daily delivery of services to users.

\subsubsection{Specific requirements in software tools procurement}

The focus was decided to be upon the following key elements:

1. Requests and workflow tracking and management

2. Raising the ICT unit productivity (reducing the number of calls, self-service, reporting)

3. Improving the service level and customer satisfaction

4. Alignment with the ITIL framework. 
Important aspects involved in the procurement of an adequate software tool, the basic need of the ICT unit in their dealing with requests, made it necessary that it should be suitable for work in solving varied incidents with the focus upon standardization and scalability, as well as on the following characteristics:

1. easy implementation

2. easy maintenance and updating

3. possibility of integration into the existing infrastructure

4. based on broadly accepted standards

5. simple and transparent to present and explain to other departments

6. intuitive user-friendly interface

From the point of view of the user of services, the requirements cover the scope of functionality, simplicity as well as the following:

1. minimum time required to present the new solution

2. intuitive user-friendly interface

3. integration with other applications (e.g., e-mail)

4. web interface that can be accessed from any location in the organization.

\subsubsection{Basic requirements for service management software}

1. Functionality - In which way the selected tools can receive and store various data, present interrelations among these data in incident-related cases and how thoroughly they can provide reports related to request management.

2. Flexibility - Refers to the ability of the selected software to host on different operating platforms.

3. Usability - How easily the application can be used in various situations of incident registrations.

4. Acceptability - How profitable the tools are if the total ownership costs are taken into consideration.

5. Knowledge - How good is the application in knowledge generating and development.

6. Maintenance - Can incident fields be added or changed in a simple manner.

7. Market opportunities - Will it be easy to promote and implement the use of the selected software with users and the top management.

8. Help system - How good is the system of help in using the tools and whether new users will be able to diagnose problems in the application and the accompanying incidents by themselves.

9. Technical Support - How much one can rely on the technical support offered by the tool provider, how often the provider issues patches and what the software updating process is like.

10. Credibility - What are the other users' opinions and experiences as regards the software and other requirements, and what is its market share.

For the purpose of these a comparative analysis, presented in Table 1, was conducted.

Table 1. Comparative analysis of software

\begin{tabular}{|c|c|c|c|c|c|}
\hline FUNCTIONALITY & HUMANWORK & HELPSPOT & HELPSTAR & TECHEXCEL & ServiceDesk Plus \\
\hline $\begin{array}{l}1 \quad \text { Ticket } \\
\text { tracking with e- } \\
\text { mail integration }\end{array}$ & + & + & + & + & + \\
\hline $\begin{array}{l}2 \text { User e-mail } \\
\text { notifications } \\
\text { about status } \\
\text { changes }\end{array}$ & + & + & + & + & + \\
\hline $\begin{array}{l}3 \quad \text { Ticket } \\
\text { management } \\
\text { reassignments } \\
\end{array}$ & + & $\begin{array}{l}+/- \\
\text { (admin } \\
\text { only) }\end{array}$ & $\begin{array}{l}+/- \text { (admin } \\
\text { only) }\end{array}$ & + & + \\
\hline $\begin{array}{l}4 \text { Ticket } \\
\text { history/log }\end{array}$ & + & + & + & + & + \\
\hline $\begin{array}{l}5 \text { Ticket } \\
\text { templates (SOP) }\end{array}$ & + & - & - & & + \\
\hline $\begin{array}{l}6 \text { Ticket } \\
\text { priorities }\end{array}$ & + & + & + & + & + \\
\hline
\end{tabular}




\begin{tabular}{|c|c|c|c|c|c|}
\hline FUNCTIONALITY & HUMANWORK & HELPSPOT & HELPSTAR & TECHEXCEL & ServiceDesk Plus \\
\hline $\begin{array}{lr}7 & \text { Ticket } \\
\text { categories }\end{array}$ & + & + & + & + & + \\
\hline $\begin{array}{l}8 \text { Ticket default } \\
\text { reaction times }\end{array}$ & + & - & & + & + \\
\hline 9 Subtickets & + & - & + & + & $?$ \\
\hline $\begin{array}{l}10 \text { Tickets } \\
\text { sorting and } \\
\text { filtering }\end{array}$ & + & + & + & + & + \\
\hline $\begin{array}{l}11 \text { File } \\
\text { attachments }\end{array}$ & + & + & + & + & + \\
\hline $\begin{array}{l}12 \text { Change } \\
\text { control }\end{array}$ & + & - & - & $+/-$ & + \\
\hline 13 Approvals & + & - & - & + & + \\
\hline $\begin{array}{l}14 \text { Business } \\
\text { rules }\end{array}$ & + & $\begin{array}{l}\text { - } \\
\text { (escalatio } \\
\text { n only) }\end{array}$ & $\begin{array}{l}\text { - } \\
\text { (automation } \\
\text { only) }\end{array}$ & + & + \\
\hline 15 Reporting & + & + (poor) & + & + & + \\
\hline $\begin{array}{l}16 \text { Knowledge } \\
\text { base }\end{array}$ & + & + & + & + & + \\
\hline $\begin{array}{l}17 \text { User } \\
\text { interface }\end{array}$ & + (client) & + (web) & + (client) & + (client) & $+($ web) \\
\hline 18 Reminders & + & + & + & + & + \\
\hline $\begin{array}{l}19 \text { Electronic } \\
\text { forms }\end{array}$ & + & - & - & $\begin{array}{l}+/- \text { (custom } \\
\text { field) }\end{array}$ & +/-(custom field) \\
\hline $\begin{array}{l}20 \text { Asset } \\
\text { management }\end{array}$ & + & - & + & + & + \\
\hline 21 Flexibility & + & - & $+/-$ & + & $+/-$ \\
\hline $\begin{array}{l}22 \text { Extra } \\
\text { features }\end{array}$ & $\begin{array}{l}+ \\
\text { calendar } \\
\text { based } \\
\text { assignment }\end{array}$ & & - & & \\
\hline $\begin{array}{l}23 \text { Easiness in } \\
\text { installation and } \\
\text { configuration }\end{array}$ & ------- & + & + & - & + \\
\hline 24 Maintenance & + & + & + & + & + \\
\hline 25 Price & $\begin{array}{l}40 \text { 000 PLN } \\
\text { netto server } \\
\text { up to } 40 \\
\text { users }\end{array}$ & $\begin{array}{l}175 \$ \text { per } \\
\text { IT user }\end{array}$ & $>10000 \$$ & $9000 £$ & $\begin{array}{l}15000 \$ \text { or } \\
3000 \$ / \text { year }\end{array}$ \\
\hline $\begin{array}{l}26 \text { General } \\
\text { impression }\end{array}$ & + & $\begin{array}{l}\text { Quite good } \\
\text { for simple } \\
\text { solution }\end{array}$ & $+/-$ & $\begin{array}{l}\text { + ver. } 1 \\
\text { comprehensive }\end{array}$ & Very good \\
\hline
\end{tabular}

Following a thorough analysis of all the general and specific requirements and after the 21 point analysis presented in Table 1, the ICT unit decided to buy the "Service Desk Plus" software tool, produced by "Advent NET" of the Zoho corporation.

\subsection{Implementation}

In introducing the ITIL solutions to software tools the project management mainly relied on the support of their closest collaborators who, in addition to their daily work, invested their enthusiasm and time to realize the vision of IT service management, especially in the management of the "Service Desk" section of the information and communications technology unit. During the implementation the team made use of two most important hypotheses: 
1. The e-mail service is the most important user - ICT Service Desk integration.

2. All requests, regardless of the manner in which they were communicated, are to be registered in the system.

\subsubsection{Implementation proposal and plan}

The proposal for the implementation of the "Service Desk" IT requirements management process support software was presented in two phases: 1) Implementation for the ICT department and 2) Implementation and announcement within the organization.

The first phase was that of the "Service Desk Plus" software tools installation and the following proposals were accepted:

- Integration of events in service management with the other surveillance system tools (e.g., automated

ticketing system ${ }^{20}$, integration with remote control tools, external data, etc.).

- Evidence of the ICT inventory as a single instance within a single software tool (a single data source).

- User requests and workflow ${ }^{21}$ management.

- Request escalation and closure.

- Information management.

- Volumes, scope of work, performances, trends.

- Possibilities of creating adapted forms.

- Simplicity in adjusting the presentation.

The second phase involved the analysis of the sofware tool offer on the market, on the basis of which 5 were selected for the comparative analysis (Table 1).

The following document (Table 2) presents the activities of project status planning, coordination and tracking, as well as the incumbents who have their tasks and participate in the team work. The basic means used in technical support and request management are the software tools that are simultaneously the drivers of the whole system. The "Service Desk Plus" was adopted, produced by the Zoho Corporation. Table 2 shows the dynamics of implementation together with activities and responsibilities.

Table 2. Activities Gantogram

\begin{tabular}{|c|c|c|c|c|c|c|c|c|c|c|c|c|c|}
\hline \multicolumn{14}{|l|}{ Year 2008} \\
\hline & \multicolumn{6}{|c|}{ Half-year 1} & \multicolumn{6}{|c|}{ Half-year 2} & \multirow[b]{2}{*}{ Responsible body } \\
\hline Title of activity & 1 & 2 & 3 & 4 & 5 & 6 & 7 & 8 & 9 & 10 & 11 & 12 & \\
\hline Planning & & & & & & & & & & & & & $\begin{array}{l}\text { ODIHR management and } \\
\text { system support } \\
\text { assisstants }\end{array}$ \\
\hline $\begin{array}{l}\text { Testing the demo } \\
\text { system }\end{array}$ & & & & & & & & & & & & & ICT user support \\
\hline Installation and testing & & & & & & & & & & & & & $\begin{array}{l}\text { Consultant firm + System } \\
\text { support assisstants }\end{array}$ \\
\hline $\begin{array}{l}\text { Configuration and } \\
\text { documentation }\end{array}$ & & & & & & & & & & & & & $\begin{array}{l}\text { All ICT collaborators of } \\
\text { ODIHR }\end{array}$ \\
\hline Service desk training & & & & & & & & & & & & & $\begin{array}{l}\text { Training during } \\
\text { implementation }+ \text { online } \\
\text { courses and help system }\end{array}$ \\
\hline $\begin{array}{l}\text { Verification and } \\
\text { starting the exploitation }\end{array}$ & & & & & & & & & & & & & $\begin{array}{l}\text { ICT department, } \\
\text { everybody }\end{array}$ \\
\hline Project closure & & & & & & & & & & & & & $\begin{array}{l}\text { ICT department, system } \\
\text { support }\end{array}$ \\
\hline
\end{tabular}

${ }^{20}$ Ticketing system - an integrated problem solving information system. Each request is one "

${ }^{21}$ Workflow 
The IT department's business policy is based on the principles of team work and information sharing, of experience and knowledge exchange throughout an integrated system of ITIL service management tools. The project earned benefits to the organization in that it helped improve efficiency, effectiveness and the quality of service delivery, while, on the other hand, earning the ICT unit numerous benefits and facilities in user request management, reporting and tracking resources, capacities, utilization level, availability, etc.

\subsubsection{Processes of configuration, service level agreement and service catalogue}

The decision that all the shared services should be stored within the service catalogue was made following the agreement with the top management. It was agreed that the catalogue was not to be in the form specified by the ITIL standards, but on the basis of the document titled "Regulations and rules of organization and instructions entered under the number 13" that defines the standard of services provided by the ICT unit, explains the rules for ICT resources use and the services the ICT unit provides within the organization.

The project document, the agreement with the top management, specifies that all the documented services are to be available $95 \%$ of the time as well as that certain services are entitled more priority than others. The agreed service levels by categories have a defined time and the execution deadline. On the basis of these predefined values the application records the time consumed on each request.

SLAs are signed by the shared services department and the providers of goods and services.

Outsourced services refer to certain service providers engaged in work on the systems that themselves provide services to the business systems that in turn provide services to the ODIHR Office users, namely:

- Telephone VolP system with "Cisco Call Manager" management

- Software and hardware supply

- Hardware repairs and maintenance agreements with companies

Other documents related to the agreements on services concerning outsourced services are also logged and available for review in the system. Part of the agreement and details of the agreement are shown in the Service Desk application where we can see details of the agreement, whether the agreement is active and who is in charge of performing the contracted services. There is also a series of related reports that can be generated for each incumbent. The reports disclose the comments regarding the services provided, the time of delay in service provision and other details.

All other services that are a constituent part of the description and execution tasks of each individual and are provided by the ICT unit are included into the matrix under the title of "skill matrix".

The skill matrix is devloped in a form of graph showing ICT department employees and a vertical support to services. The service catalogue shows the support to applications that are employed within the business departments of finance, transport, the director and the document distribution. Characteristic of these applications is that they are developed by the application development unit and that, in addition to maintenance performed by the ICT department, they include one business moderator/user each.

\subsection{Incident management}

One very important statement the ICT unit manager during the implementation that directly refers to availability management and is related to user support service says: "Some employees in the ICT department claim that they were burdened by an enormous number of requests, however, the reports we retrieved from the request management application for that particular period of time showed that it was absolutely not the case."

This statement highlights the dimension that covers the service control and strengthens the authority of both the ICT unit manager who can track what is going on in the service desk section and the users who manage incidents, problems and actually all the clients' requests. It was also difficult to agree on the Service Level Agreemnents (SLA), hence a SLA was created based on asigning priorities to service requests. Hereinafter the incident management and the priority assignment process will be described. 


\subsubsection{Incident management requests}

Requests were stipulated in the following items of configuration: request type, status, ways in which requests are sent, service level, urgency, priority, owner, service requestor, category, subcategory.

\subsubsection{Request types}

Requests are dealt with in accordance with the types identified upon the reception of the request at a single e-mail address integrated in the "Service Desk" software tools (hereinafter, SD) and the database itself. The SD application requests are classed into types that are created in accordance with the requested service where we distinguish:

Incident: An event that is not part of the standard services operation and that causes or may cause the failure or a reduced quality of the service and the user's productivity.

Request for service: Request for change, shared or direct, may be conceptualised in such a manner that it is promoted into a service. The request for service is characterised by the fact that the request change may be effected under a strict, well defined procedure control. It is in this way that risk is reduced.

Request for information: Request for information concerning the ICT resources. The user requests from the ICT unit information on resources or activites.

Proposal: Proposal is a request for improvement of service and is submitted by the "Service Desk" technician.

\subsubsection{Shared system incidents, change, creating new request ${ }^{22}$}

Shared system incidents are the responsibility of the "Service Desk" section and are prepared by the SD system administrator. The shared system incident is an incident affecting a group of users or the entire organization. The shared system incidents are processed in the following manner:

- Adjust "Chief ICT Unit" (from the drop down list) for the service seeker.

- The impact of the incident as well as the urgency in the majority of cases are to be "Affects Organization", Urgency "High".

- Categorisation, solution updating, etc. are to be revised before closing the request.

- Anticipate the time of stoppage, "downtime", and write the description in "description". Write in the accurate phrase of the reason for stoppage and the time when the servise was hit. The downtime is counted from the moment of the user's initial request until the moment at which the ICT unit (ODIHR ICT) sends information that the service resumed activities.

- In case of "major incidents" where global services are hit, downtime is estimated on the basis of the notification by the ICT unit of the OEBS Secretariat in Vienna received via e-mail.

Shared system incidents are generally followed by short meetings of the ICT group where the causes for the incidents are analysed and possible solutions are proposed. The meeting is scheduled after the first SLA escalation (4 hours upon expiry, in case of key systems). At the meeting, a decision is made as to whether there is a need to launch the system recovery procedure.

\subsubsection{Possible request statuses}

The request status is used to denote the level of improvement in case solving. It is based on the option that can be selected for the presentation of the request status during and after the solution process is over. Grouping requests according to type helps organize requests correctly and prevents chaos in the review of

${ }^{22}$ In ITIL terminology, Major Incident 
the requests. The following are the statuses via which we can track and control the requests that are processed in the system at one moment:

"Open" - The status is assigned this default value folowing the creation (automatically or manually). It denotes that the request is open and that the solution to the case is being worked out.

"On hold" - The request waiting to be accepted by the system, the ICT assisstants, the user or the external collaborator.

"Resolved" - The request that is processed and resolved.

"Resolved on first contact" - The request that is processed and resolved at once or immediately upon the first interaction. For example, the user contacts the ICT unit, reports the incident and the incident is solved immediately on the basis of the received information.

"Closed" - Closing the request is used with utmost care. Explanation: requests with this status are closed in specific cases, such as: when on the basis of the user's initial request the technician requires additional information without which he cannot resolve the case or when this information is necessary so that the case resolving can be resumed (at this moment the status is "on hold") and does not receive any reply in 30 days. Another situation is when the user that has sent the request realises that the request is no more relevant for him and notifies the technician to close the request. Similarly, this status can be used in information messages that are the result of general information sent by a department or when the request could not be resolved.

\subsubsection{Ways of incident reporting and service requesting}

There are several ways in which a certain service can be requested or an incident reported, such as:

Telephone call - After the telephone call made by the service user, the request is logged by the ICT technician. Important: Any telephine calls requesting the Service desk action are to be logged in the CD application.

E-mail (default option) - Once the e-mail message gets into the odhir_it@mailbox, the users automatically get a feedback e-message that their request has been successfully received (automatically prepared message). Similarly, a request is automatically generated that immediately fills in the fields in the request which will thus be marked by the name, time and the e-mail sender. Users are continually directed and encouraged to send their requests in this way.

"Walk-up“ request - The request is registered by the technician after the conversation with the user.

Web request - the request is registered /logged by the user, via the online interface.

\subsubsection{Complexity level of requests in processing incident requests}

The complexity level of requests refers to the selection of complexity level of requests when registering them. The decision is made by the technician who monitors notifications and then decides to undertake a certain action. According to this criterion, requests are classed as follows:

Simple action - The action undertaken by the technician to resolve the incident. This mostly refers to requests that are resolved on first contact. This type of action does not require collaboration with other technicians of the second or third levels of support.

Simple troubleshooting - A simple method of problem solving undertaken by the ICT technician. This type of problem solving does not require consulting or collaboration with the ICT technicians of the second or third levels of support either.

Complex troubleshooting - This method of problem solving is more complex and generally requires the support and collaboration from other ICT technicians. It takes more time in comparison with the standard request resolving procedure. 
Extensive troubleshooting - Problem solving requires collaboration with other technicians, the employed at the ICT head office or a third party and this is by far more time-consuming than resolving standard requests.

\subsubsection{Effects of incidents upon business}

Incidents may affect:

Organization - the request affects the entire organization,

Group - the request affects a group of users (e.g., the entire department),

User - the request is related to one user.

\subsubsection{Incident urgency}

Urgency refers to the importance of the request and requires efficiency in handling the incident. The system defines three levels, as follows:

High - no need to search for a temporary solution, it is critical functions that are affected and in an important period for a VIP user.

Normal - some temporary solutions are implemented.

Low - the user can continue using the services (vital functions are not affected and the users work is not slowed down).

\subsubsection{Service request priority}

Priority is a combination of impact and urgency. Priority has a predefined configuration and is automated. In any case, priority can be changed by the user or the technician following the creation of the request or in the course of case resolving process. Figure1.referrs to the impact and urgency ratio of the request upon certain categories.

\begin{tabular}{|l|c|c|c|}
\hline & \multicolumn{3}{|c|}{ Urgency } \\
\hline \multicolumn{1}{|c|}{ Impact } & High & Normal & Low \\
\hline Affects Organization & 4 hours & 8 hours & 12 hours \\
\hline Affects Group & 8 hours & 12 hours & 36 hours \\
\hline Affects User & 12 hours & 36 hours & 48 hours \\
\hline
\end{tabular}

Figure 3. Impact and Urgency Ratio

\subsubsection{Service request owner}

The request owner can be:

- a group of ICT technicians and

- a technician

\subsubsection{Service request user}

A service requester is a person employed by the organization that can send a service request via the above described methods. This person is the request user. 


\subsubsection{Categories and subcategories of requests}

All requests are classed into different categories and subcategories. This classification can be broadened or narrowed, as the case may be, and the authority to change or update it is that of the system administrator's. The characteristic of this classification is that it is essentially a sort of service catalogue. Naturally, new categories emerge in time and the old categories and subcategories may be written off and cancelled. The service catalogue structure is designed in such a manner that each item in the configuration is supplied with a description as well as with defined procedures and configuration items in case of automated processes.

\subsubsection{Default values of requests}

Values can be changed via an adequate selection of the item from the drop-down menu, such as, for example, the complexity level of request, the type of request, impact and urgency. The system can contain items with predefined values that can be changed by the technician either on registering the request or later. One method of registration is the following:

Request type: service request

Manner: simple action

Impact: user

Urgency: low

Priority: low

\subsubsection{Request closing rules}

The request closing rule is used when the work on the case is completed. For the final closing of the case and its marking as resolved some mandatory fields have to be filled by the technician. If not, the system will not allow the request to be closed. The following fields are considered to be mandatory: manner, category, subcategory, time consumption, impact, related tasks, level, technician, priority, urgency, request type. The technician cannot close the request unless he/she enters the time consumed in its resolving.

\subsubsection{User notification rules on current requests}

Notification is enabled directly from the CD application. The status of the service request is tracked and the technician does all the correspondence with the user from the CD application. Upon closing the request by the technician the system generates an e-message that the CD application automatically sends to the user notifying him that the work on his request (case) is completed, with a number of additional details enclosed (telephone number, request number, time consumed, additional possibilities and request review).

\subsubsection{Request life cycle}

A large number of requests are expected to be created automatically, retrieving the incoming e-mail to the odhir_it@osce.org address. Earlier in this paper the possibilities of request creation and its further processing were described. One manner of creating a request is that the technician creates the request manually, that is, registers the user request reported via telephone or via a web port.

\subsubsection{Creating a request manually}

When the user decides to create a request manually, he/she accesses a form at the web site and fills in the basic data in order to create the request. This is one of the most elementary methods of request creation by the service users. The request creating page is part of the service system. The other method of the manual request creating happens at the moment the user calls the Service desk; the technician answers the tele- 
phone call and registers the request in the SD application via a form in which he fills in all the relevant details that the user supplies. Upon creation, the request can be reviewed in the system.

\subsubsection{Request process flow}

Once the request registration is completed, whether by the system or manually, and all the fields are adequately filled, the request is ready for further processing. The following possibilities are available: correspondence with the request sender, request forwarding, searching for a solution in a case base and transferring the solution to the request, reply to the requester with the resolution contents enclosed, registering the time of the work order.

During the life cycle of the request, since the moment it is created in the system until the moment it is marked as resolved, the technicians may change the request attributes as well as delegate the request to other technicians. The diagram below presents the overall flow of the request resolution process.

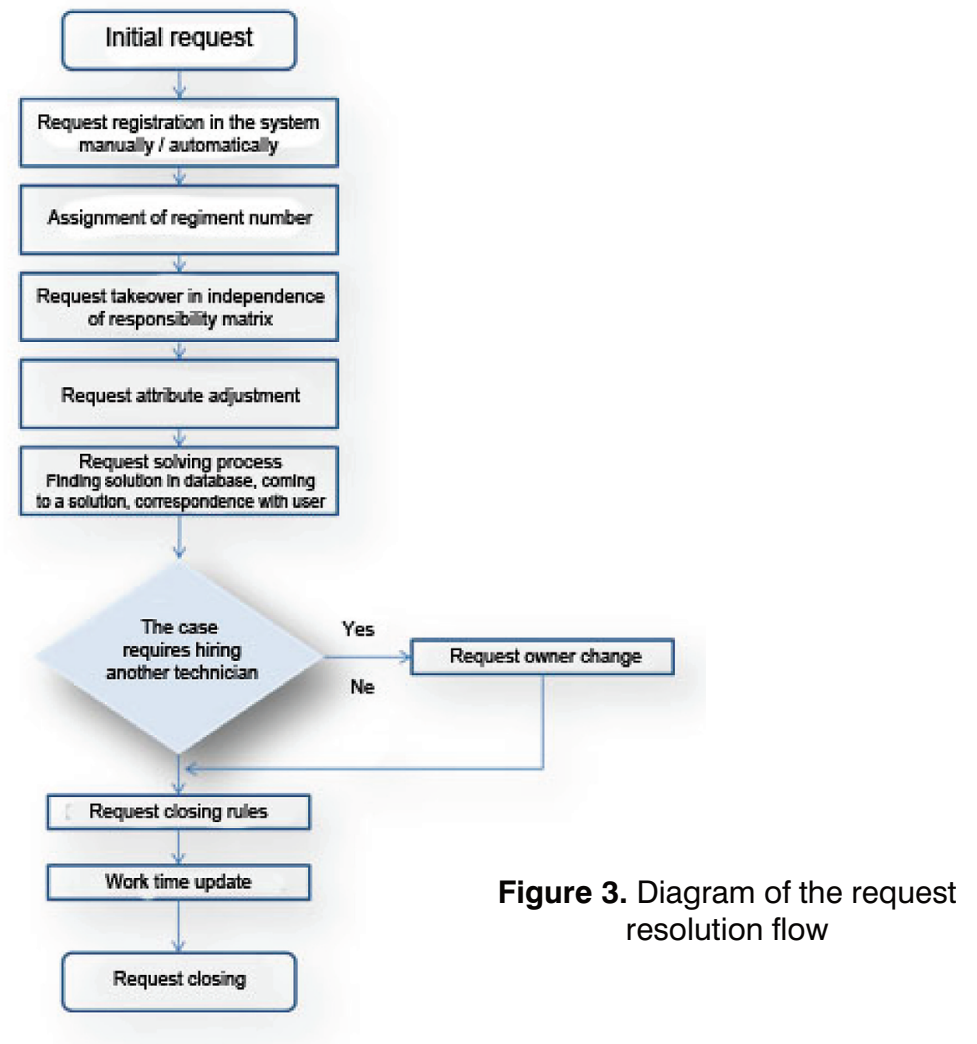

\subsection{Standard operating procedures}

One method to resolve the request consists of the information gathered through experience and systematic work, a set of tasks presented in the form of procedural knowledge. There is a large number of tasks that repeat daily, however, they were not well organized nor structured in the previous service management system. These tasks are documented in the form of standard operating procedures.

The basic reason for introducing procedural knowledge in the form of instructions is that it improves the service and the initial reactivation of daily operations, from the moment the fully employed person starts work, during his work, and on the expiry of his contract. In other words, these procedures help through systematically and structurally presented instructions to the technical support unit employee as to the manner 
in which certain business tasks should be accomplished. These tasks may be: changing work station, request for non-standard software installation, user creation in an active directory, hardware management, server closing procedure, data erasing, making reserve copies on the server, router, firewall, issuing equipment to users, procedures to follow in case of system failure, guest account creation, tests, training, user management, data restore instructions, etc.

\subsection{Problem management}

\subsubsection{Problem management mission}

The mission of the problem management process is to reduce the number of incidents and thus improve operations and IT performances.

\subsubsection{Problem management description}

The truth is that incident and problem management are two separate processes, however, they are closely connected and use the same tools as well as the categorisation, impact and codes of the priority assigning system. Four procedures have been developed as part of the problem management process:

1. Support Request Review - This procedure is used by the managers dealing with problem processes, when support requests are being considered in order that problems within the services they are responsible for should be identified.

2. Root Cause Analysis - This procedure is used by the managers and problem specialists in the course of problem analysis.

3. Analysis Review - This is conducted by the managers upon obtaining the results of the root cause analysis.

4. Problem closure - This procedure is used by the managers who close the process.

The diagram (Figure 4) presents the problem management procedure that falls into the category of reactive methods and is performed as part of the operations.

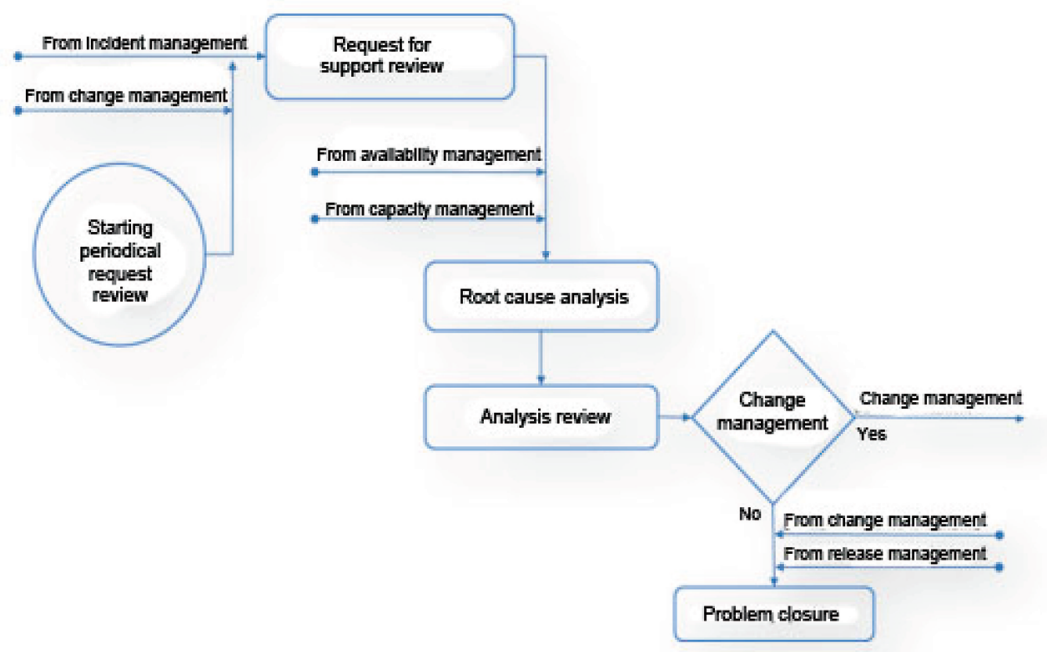

Figure 4. Problem management flow diagram

\subsubsection{Support Request Review}

Information obtained from the request is used to identify the problem. The most important tools used for this purpose are the search and the functionalities that are part of the service management SD application itself. A specialist who is also involved in problem solving may draw attention, and it would be useful to take into 
account his expertise and experience, to certain requests that can be a problem. The role of the specialist is also to identify and escalate the problem that is to be solved.

Upon identifying the problem, the specialist or the "problem manager" registers the problem in the SD application for service management. The manager dealing with the problem proceeds to analyse the problem. In the next step, the "problem manager" or the specialist in charge of the problem defines the adequate severity level ${ }^{23}$ and links requests that are related and conneced to the problem. Then the analysis is resumed. After a period of time, if another request is identified that is related to the registered problem, this request is also linked.

\subsubsection{Root Cause Analysis}

The problem manager analyses the details of a given problem and, in case he identifies one or a number of incidents resulting from the problem, tries to provide a temporary solution.

Information on the solution, and especially the method in which it will be implemented, is added to the solution of the problem. This temporary solution may be implemented in solving the future incidents caused by this problem until the structural solution has been worked out and implemented.

In the following step the changes that occurred are tracked and incidents are analysed until the root cause is identified. On identifying the root cause the case is updated and is complemented with a description and explanation.

Further, possible structural solutions are analysed and evaluated. The description of each option is added to the case, together with a recommendation on a desirable and structured solution.

In case change management does not require a permanent implementation of the temporary solution or eradication of the problem cause, a desirable structured solution is implemented. If the problem manager is not in a position to identify the root cause of the problem or if he proposes a structured solution, he must note this as a reason for which the problem cannot be solved.

Regardless of whether a structural solution is proposed or already implemented, the problem manager updates the problem case status in order to inform the specialist who is also engaged in problem solving that he has completed his share of work.

\subsubsection{Analysis Review}

Upon the completion of the root cause analysis the decision is made as to whether the structural solution is proposed or it is already implemented. In case the problem was already solved without change management being necessary to coordinate the structural solutions implementation, the manager working on the problem directly closes the case. The case is also closed if a thorough analysis has been conducted but no practical structural solution could be proposed.

In case the programme manager has proposed a practical structural solution but has not implemented it because he believes that change management is necessary, the problem owner checks whether the change management is really necessary. If that is not the case, the problem manager solves the problem. If change management is necessary, the problem manager will register/log the change of the contracted service.

In case the analysis of the problem proved to be inadequate and unacceptable, the problem owner again assigns the problem to the same problem manager or to another member of the team so that a better analysis be conducted.

\footnotetext{
${ }^{23}$ The severity level can be high, medium and low (from SD application) and is selected from the down-fall list of the options offered.
} 


\subsubsection{Problem Closure}

Once the change is implemented, and in order that the problem be solved successfully, the problem manager checks whether the problem was really solved by implementing the change.

In case the implementation of the solution suggests that the problem is solved, the problem manager closes the case.

Further, in case the change is not implemented or the problem is not solved through the implementation of the solution, the problem manager decides whether another structural solution to the problem can be proposed. If that is possible, the problem manager again assigns the problem to the specialist in his group that will be engaged in solving the problem.

Alternatively, if it is obvious that no practical method of a permanent implementation of the temporary solution or for the elimination of the root cause is available at the moment, the problem manager updates the case to point out that the problem has reached a dead-end path. It is his obligation to periodically attempt to find other ways and request a new analysis for the reason that another approach or another technology may be available that could help reach a practical structural solution.

\subsubsection{Problem management scope}

The problem management scope is confined to the problem that can be identified on the basis of information collected from the registered requests and the problems identified by the capacity management and availability management.

\subsubsection{Roles and responsibilities in problem solving process}

Table 5 illustrates the roles involved in the problem management process together with adequate responsibilities.

Table 3. Roles and responsibilities in the problem solving process

\begin{tabular}{|l|l|l|}
\hline Role & Responsibilify \\
\hline Problem Manager & - Analyses user support requests related to service(s) for which he is responsible as a \\
& problem manager, in order to identify the problem. \\
& capacity and availability management processes, are improved in the problem \\
management process, timely and on the priority principle.
\end{tabular}


When we tackle a problem, we come upon information, data, analyses, solutions, tasks and incidents that caused the creation and registration of this problem. The problem also contains items rather similar to those of the incident: category, subcategory, status, prority, etc.

\subsection{Change management}

\subsubsection{Service change process mission}

The change management process mission is to adopt and implement change in a most efficient manner, while minimizing the negatice effects upon users during the implementation. All changes in the "production" environment are to be conducted in a defined and predetermined manner, with the exception of the predefined and previously approved of standard changes. Most important in the implementation of this section of the ITIL solution is that the system is established in such a manner that any change in the system has as minimum effect as possible upon a normal functioning of all the services stipulated in the SLA phase as well as it remains within the range of agreed values.

\subsubsection{Description of service change process}

The change management process consists of four procedures used in the implementation. In the present moment the methodology of urgent changes has not been developed yet, hence its elaboration will not be considered in this section. The graphic presentation of the process is presented in Figure 5.

The first procedure. This procedure is called the Change Registration and is in charge and launched by the Change Coordinator. This procedure is launched by the change coordinators in working with the requests for change. The procedure is combined with "change planning" and involves change coordinators and the specialists that prepare the planned changes within their fields of activities and responsibilities.

The second procedure. This procedure is called the Change Approval and is used by the Change Owner and the Change Advisory Board (CAB) (e.g., the service owners and providers). The change owner has a decisive power as the highest authority that approves of the change on the basis of the board members' attitudes.

The third procedure. This procedure is called the Change Implementation. It is used by specialists to implement the change within all the ICT fields (infrastructure, services, applications, etc.).

The fourth procedure. This procedure is called the Planned Change Closure. Specialists use it after they have conducted the final test in the system and upon the completion of the implementation. It is also used by change coordinators to close the change process. 


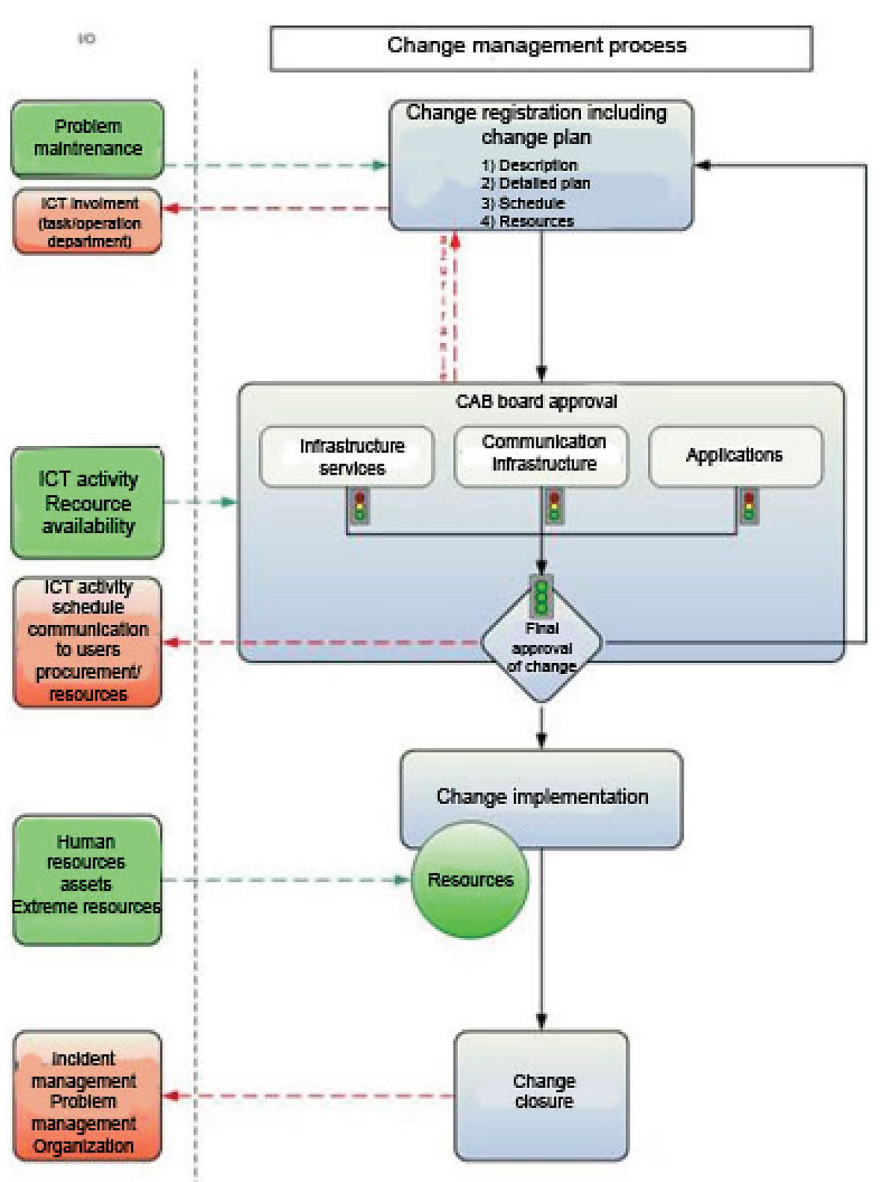

Figure 5. Change management process

\subsubsection{Change registration}

Change coordinator may receive the requests from the following sources:

- Incident management, in the form of a request,

- Problem management, in the form of the problem assigned the status of change requested,

- Maintenance, in the form of the document describing the need for change and its requirements,

- Organization/Operations, the form for the business process change.

The change coordinator's task, on receiving the request for change (RFC), is to decide whether it is necessary that the new request should be added to an already registered request. In case the existing request is adequate or is very similar to the request registered before, he will add it. Thus the efficiency of the request for service change management is improved.

In case he receives a request for a standard change, the coordinator uses the SD application to register the new change and links the new request or problem for this change. It is also the task of the change coordinator to enclose the list of resources and a detailed work plan to the request.

Organizational change often causes stress and confusion among the employees and managers. In this way the process is structured in the form of a road map in order to address challenges and define the mechanisms for identification, evaluation, decision-making, change tracking, apprehending and solving problems and other issues. A good plan to revert changes should include:

- A lower level technical support,

- Specific instructions for communication with contacts. 
A list of technical instructions is created for the purpose of establishing the order of activities via which the implementation plan will be reverted and explaining the manner in which changes are to be reverted for each of the steps in the implementation.

An example of a simple plan of change reverting is as follows:

1. Notify the Service Desk about backup plan initiation. o (Call them, send an email or send a request - state it specifically.)

2. Disable user access to the system. o (How? Make a list the actions.)

3. Restore backup taken before the change implementation o (List the actions needed.)

4. Conduct system health checks. o (List them all.)

5. Enable user access.

6. Notify the Service Desk of successful backup.

However, often the plan will be more complex than it would seem. There might be many more restoration steps, involving various databases, file systems and other areas of the IT infrastructure. The basic template is still important. It needs to be detailed and tailored to every organization and every change. Needless to say, every action should have an owner, so that it is clear who does what.

It is also important to insist on an efficient communication with the Service desk. Communication aspects need to be in the plan to maintain control over the situation. Moreover, the business needs to know IT is in control. The Service Desk should take care of projecting the image of control towards the business by issuing regular communication if changes have had an impact upon the business. They will also take calls from dissatisfied users and inform them about the solution status.

In case the request for change is not a standard change, the coordinator checks the request to make sure it complies to the internal standards and the business policy. In case the request for change fails to comply to the rules, the user is notified about it and given the explanation that the request is in conflict with the standards. If there is no conflict, the change coordinator decides whether change implementation really needs to be coordinated by change management.

This is only necessary when change can cause the following:

- Degradation or an overall unavailability of the service,

- The functionality of the service is altered,

- Writing off the service,

- Introducing a new service.

In case the change can be implemented without change management participation, the coordinator refuses the request for change and notifies the requester that the change is not necessary.

On registering the change, the coordinator conducts a risk and impact analysis to collect the necessary information, so that the change of the implementation plan can be created to reduce the risk of failure and impact upon user(s).

\subsubsection{Change approval}

On completing the risk and impact analysis and upon developing the implementation plan, the Change advisory board analyses the change. In case the Board decide that the proposed change is in conflict with internal standards and policy, they advise the coordinator that the change cannot be implemented. If the 
change is not in conflict with any internal standards and policy, the board reviews the risk and impact analysis and the implementation plan. The board then check the plan to ensure that adequate measures are taken for the purpose of minimizing the risk of failure and impact upon user(s), as well as that preparation time is not in conflict with other planned changes and events. If the risk and impact analysis and the implementation plan appear to be appropriate, the board members approve of the change.

In case the analysis conducted is not sufficient, the Board requires that the coordinator performs additional analyses. Similarly, if planning has not provided an adequate answer to the issues of risk of failure and impact upon users, or if the plan is in conflict with other planned changes or events, the change manager requires that the coordinator adjusts the implementation plan. Approval has to come from all the board members.

In case the change is refused by any member of the Board, the Board requires the coordinator to conduct additional risk and impact analyses for the purpose of aligning the plan (if that was the reason for change refusal). If change is approved of by all the mambers, it is transferred to the change owner for the final approval. In this part, the specialist prepares the implementation to ensure the operational readiness of change. This may mean purchasing hardware, test environment configuration, conducting various tests, etc.

\subsubsection{Change implementation}

In this part, the specialist prepares implementation to ensure the operational readiness of change. This may mean purchasing hardware, test environment configuration, conducting various tests, etc. Figure 6 presents the change process concept and the method of the service change implementation.

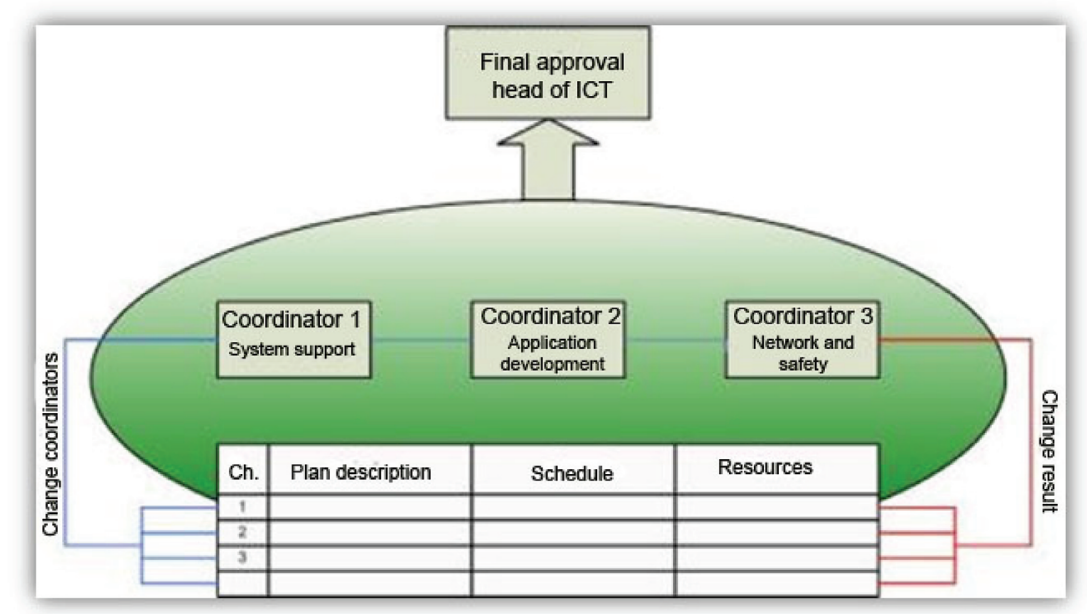

Figure 6. Change process concept in the ICT unit of the ODHIR institution

On submitting, analysis and discussion of the changes, the head of the ICT department approves of the service change. When everything is ready, the specialist implements the change in accordance with the change plan.

\subsubsection{Change closure planning}

On implementing the change, the specialist uses the help of a user if he himself has no right to access, to check whether the implementation has been successful.

Information in the organization's documentation is updated if necessary, if the specialist decides that all the change requests have been fulfilled. The service owner subsequently notifies the requester and all those who approved of the change about the success of implementation. On completion of this task the change coordinator closes the case. 
In case not all the requests are fulfilled, however, the specialist who conducted the tests decides whether it is necessary that the change be reverted and returned to the initial status. If the change does not ensure improvement in comparison with the previous situation, or if it causes safety risk or the data integrity risk, it is reverted.

In certain situations there is still a chance that change implementation will be successful. In such a case the change coordinator creates and assigns the necessary additional work orders. However, if it is not clear in that moment how all the needs in the request will be fulfilled, the change coordinator notifies the requesters and approval givers on the situation and closes the change.

The change output has to be adopted by the service change owner.

\subsubsection{Change process scope}

The change management implementation scope is implemented in case of:

- Unavailable or degraded services during the working hours,

- Functionally altered services, i.e., services that have lost their purpose,

- Service write-off,

- Introducing a new service.

\subsection{Preventative maintenance management}

Preventative maintenance allows for repetitive tasks and tasks critical to an uninterrupted functioning of services to be accomplished in precisely determined time periods. The scope of jobs defined in this maintenance method involves all aspects of business and the processes related to software maintenance, change of configuration, change implementation, resource management (hardware, IT unit storage), preparation of weekly, monthly and annual reports, planning everyday activities of short-term loans of equipment, tasks of safety maintenance, log files control and other activities.

In so clearly defined a process the responsibilities are clearly allocated to individuals. There is a notifying configuration for each task, generated by the system itself in a precisely defined time. Notification is sent in the form of electronic mail to a predefined address (mentioned earlier in the paper) and an adequate active request is created in the SD application, with an open status.

The process is semi-automated since on completion of the request-related jobs the request has to be closed with an explanation, if any. If a technician in charge of a certain preventive maintenance task is not capable of completing the concrete task in a defined period of time, he has to assign the task to another technician, together with the explanation. The importance of registration of every request was discussed earlier in the paper, as well as the matrix that specifies the responsibilities of each individual in the ICT department.

\subsection{Reporting and surveillance}

Achievement is measured in relation to the defined goals in the project. When this is proven, new goals in service improvement are defined as a constituent part. To prove that results are achieved, the key performance indicators (KPI) are to be constantly tracked. The key performance indicators also include customer satisfaction, so once the results are obtained, there is no need to enquire with the users in various phases whether the implemented changes improved their perception of service quality. In some cases it has been concluded that it is very likely that the ICT department achieved a higher availability, that there are fewer incidents and that the response time is improved, however, the perception of service quality is not improved. It is clear that this is equally important and such problems have to be resolved in interviews with the users. On the basis of the ITIL implementation principles some of the basic questions are brought up: Why measure? What is to be measured? What can we measure? 
The answer to the first question was devised in the following way:

- Set guidelines for activities meant to achieve the set goals,

- Use facts to prove that the action flow is necessary.

- In order to act we have to determine the point of intervention including subsequent changes and corrective actions.

The answer to the second question on what is to be measured is:

- Critical elements of services delivered to users (KPI)

- "Soft" indicators of performances, e.g., user satisfaction.

The answer to the third question on what we can measure is:

- Administrative instruction (corporate policy of information system safety), item $6.11^{24}$,

- Users are granted access to shared computer systems for at least $95 \%$ of standard working hours, item 6.11.1,

- The number of received requests by type (request for service, incident, request for information), etc.

The preparation of reports on Service desk activities is done every Thursday in a week, where the entire group meets, together with the head of the department. The manager opens the meeting stating the most important aspects, starting with the report on ICT activities on the issue of incidents. The first line support technicians (2 technicians) present the reports on the overhead projector. Also analyzed are the monthly reports on service availability, incidents by category and requests by type.

\subsubsection{User satisfaction as performance indicator}

User satisfaction is one of the key performance indicators and is highly important when it comes to asserting that the implemented change improved the perception of service quality.

In order that ICT operative business be assessed, research was conducted and a questionnaire was created available on a corporate port and via e-mail, where users were asked to fill in the questionnaire. The questionnaire was available to the employees and processed in the period of one month.

The research included the period of the initial implementation of the IT framework project and the indicators were oriented towards improving the aspects of ICT services business doing.

The questionnaire consisted of the following questions:

- Preferred way of contact (telephone, e-mail, in person).

- Was the latest problem solved?

- Did you get information on ICT services when you began to work in the organization?

- Are you familiar with the rules and procedures on the ICT resource use in the organization (document, Code on the use of ICT resources of the ODIHR)?

- Overall assessment of the ICT department activities?

- Users' comments.

\footnotetext{
${ }^{24}$ The document of the organization that defines the user access and authorization to systems. This act obliges the users as to the use, rights and corporate safety regulations. Concretely, in this case it is the passwords and rights to access, identity, complexity rules of access passwords, ban on the password use and keeping and other regulations.
} 
The questionnaire revealed the following key findings and starting points for service improvement:

- Users stated that telephone is the most desirable method of communication. o Revision was planned to create a single number for users' calls, \#3333 "Service Desk", redirecting the calls to the first free line of a technician, also established was the system of voice messages available around the clock.

- Information on ICT services the users are delivered need to be improved.

o The package for presenting the system to a new user is integrated and implemented in the form of a standard operating procedure. The e-mail template with documentation is sent to the user by electronic mail and the meeting is scheduled to last 30 minutes where ICT Service desk personnel point out the basic aspects of ICT services and explains all the aspects and use of the system (navigation, safety, authentication, etc.).

- Numerous problems would be solved if obsolete hardware were replaced (desktop computers)

- The plan for replacement of obsolete technologies and hardware was devised.

- Information available on the corporate port in the form of news module.

3.9. Benefits and flaws of the ITIL solution implementation for the organization

A number of important benefits of the ITIL framework can be presented in the following way:

- Service agreements are more user-oriented.

- Better opportunity for quality, availability, reliability and cost management.

- Improved internal communication and communication with users.

- A sound basis is created for developing a more efficient, clearer structure and user-focused approach.

- A favorable framework is obtained for externalization of certain services.

- Change in the process management culture and the culture of communication with users which is now oriented towards user satisfaction, to continuous improvement of service and to the service quality.

The flaws of the ITIL framework are reflected in the following:

- Results show that a dramatic change in the business culture has caused long-term barriers to full implementation of service management. The older and more vertical the company, the longer the change resistance process.

- Risk related to overuse of the ITIL standards and generation of bureaucratic procedures that can be counterproductive.

- If the company does not dispose of the basic data, it is rather difficult to analyze results and improvements achieved.

- Commitment is indispensable at all the levels of business.

- It is not recommended to implement the framework on only one department.

- Investments and resources need to be available in order that ITIL should be improved.

- The ITIL framework concept need to be understood as the best practice library, rather than a religious document or constitution. ITIL is a framework of guidelines and if we rely on these guidelines, we will ensure an adequate approach in information technologies implementation and employment. 
Conslusion

One conclusion of the employees in numerous companies that manage services using the ITIL framework result from the belief that structured processes, procedural knowledge, preventive maintenance and adequate incident management are the backbone of a well-designed solution to management of technical and system support requests.

At the very beginning of implementation (of the framework) there are always challenges that may cause scepticism and distrust in even the most prominent advocates of its implementation. After a period of time, however, the success of the implementation surely reveal visible results. The most important step in the implementation is to win the trust and motivation of the employees who wish to take part in the system creation.

Also very important is to invest into education and stimulate the change of the employees' attitudes in a positive sense, prepare guidelines, present the basics of the ITIL framework, achieve and work on the promotion of solution visibility for the benefit of the human resource policy of the upper management, improved reporting, cost reduction, and, most important, for the purpose of improving IT service delivery.

Of vital importance for attaining the idea of ICT unit service improvement is incident management that means a continuous improvement of services, transparency, information sharing and, finally, institutional knowledge creation.

Structured and documented processes and operating procedures make indispensable guidelines to the ICT department assistants in an efficient and effective completion of tasks. Similarly, an easy navigation and case and knowledge search are easily achieved by a better categorization and authorization thereby reducing the time required to accomplish tasks and improve the data consistency and quality.

Reporting is highly important because of the future plans of the organization and the dynamic environment. Resources are better managed and the equipment supplies and inventory status can be tracked at any time.

\section{ACKNOWLEDGEMENTS}

On this occasion we would like to acknowledge the support of the Organization for Security and Cooperation in Europe, Office for Democratic Institutions and Human Rights, Warsaw, Poland and Mr Krzysztof Smolinski, Chief, INFORMATION TECHNOLOGY UNIT, Department of Common Services for their technical support, advice and valuable help in conceiving and conducting the business case study, as well as that of the ICT Service Desk Team for their technical support in completing the report and analytical data.

\section{REFERENCES}

[1] A, Tiwana. (2000). The Knowledge Management Toolkit. Prentice Hall.

[2] Applehans W:GA, L. G. (1999). Managing Knowledge, A Practical Web-Based Approach. AddisonWesley.

[3] Bečejski-Vujaklija, D. (2007). „Upravljanje IT us/ugama zasnovano na najboljoj praksi“. Beograd: INFOM.

[4] Cartlidge, Alison; Ashley, Hanna; Rudd, Colin; Macfarlane, Ivor; Windebank, John; Rance, Stuart:. (2007). An Introductory Overview of ITIL V3. United Kingdom: The UK Chapter of the itSMF.

[5] Deming, W. E. (1986). Out of the Crisis. Cambridge,, Massachusetts: Institute of Technology, Center for Advanced Educational Services.

[6] Dugmore, Dr Jenny. (2009, Jun 9). BS 15000 to ISO/IEC 20000 - What difference does it make? (The Chartered Institute for IT Enablin the information society) Retrieved Jun 9, 2012, from The Chartered Institute for IT Enablin the information society: http://www.bcs.org/content/conWebDoc/8077

[7] Euro Quality Group. (2012, June 9). Primena ISO 27001 postaje obaveznija i u Srbiji. Retrieved June 9 , 2012, from www.euroquality.rs: http://www.euroquality.rs/srp/aktuelno/?conid=579

[8] http://www.manageengine.com. (n.d.). Retrieved June 25, 2012, from ManageEngine: http://www.manageengine.com/company.html

[9] IMS Consulting. (2012, June 11). http://imskonsalting.com. Retrieved June 10, 2012, from http://imskonsalting.com/usluge/iso-27001/struktura-iso-27001 
[10] International Organization for Standardization. (2009). ISO/IEC 27000 Standard.

[11] International Organization for Standardization. (n.d.). ISO 20000.

[12] ITIL Open Guide. (2012, Jul 3). www. itillibrary.org. Retrieved Jul 3, 2012, from http://www.itlibrary.org/index.php?page=Service_Level_Management

[13] ITIL Service Management Blogspot. (2007, Septembar 25). Razvoj ITIL okvira kroz istoriju. Retrieved June 10, 2012, from http://itservicemngmt.blogspot.com: http://itservicemngmt.blogspot.com/2007/09/brief-history-of-itil.html

[14] ITIL.ORG. (2012, Jul 5). www.itil.org. Retrieved Jul 5, 2012, from http://www.itil.org/en/vomkennen/itil/index.php

[15] ITservicemngmt blogspot. (2011, Februar 2). itservicemngmt.blogspot.com. (ITIL SERVICE MANAGEMENT) Retrieved Jun 10, 2012, from ICT Service Management: http://itservicemngmt.blogspot.com/2011/05/isoiec-20000-brief-history.html

[16] KING ICT. (2012, Jul 3). http://www.king-ict.rs. (KING ICT) Retrieved Jul 3, 2012, from http://www.kingict.rs: http://www.king-ict.rs/Default.aspx?tabid=356

[17] Kit, I. V. (2009, June 15). 2009 Edition Study Guide Book and Online Course. The Art of Service Pty Ltd 2009.

[18] Kotler, P. (2012, June 16). http://www.marsdd.com. (John Wiley\& Sons, Hoboken, New Jersey) Retrieved June 16, 2012, from http://www.marsdd.com/articles/service-kotler-on-marketing/

[19] Lisse, A., \& Lisse, S. (2006). Procesi upravljanja IT uslugama.

[20] Lloyd, V., Rudd, C., \& al, e. (2007). ITIL, Service Design. London: TSO, The Stationary Office.

[21] Mintzberg, H. (1994). The Rise and Fall of Strategic Planning.

[22] Mr Aleksandar Vujović, P. d. (2007). ISO 27001 I ISO 20000 OSNOV ZA ORGANIZACIONE DOBITI. Kragujevac.

[23] ODIHR, Office for Democratic Institutions and Human Rights. (2012). ODIHR Network Diagram.

[24] Office of Govenment Commerce. (2007). ITIL V3 Service Strategy. London: The Stationery Office.

[25] Office of Goverment Commerce. (2007). ITIL V3 Service Operation. TSO (The Stationery Office).

[26] Office of Government Commerce (UK)CCTA and OGC. (2005).

[27] Office of Government Commerce. (2007). Continual Service Improvement. London, UK: TSO (The Stationery Office).

[28] Office of Government Commerce. (2007). ITIL V3 Service Design. London: The Stationary Office (TSO).

[29] Office of Government Commerce. (2007, Maj 30). ITIL $®$ V3 Glossary v3.1.24. Retrieved Jul 1, 2012, from http://www.best-management-practice.com: http://www.best-managementpractice.com/gempdf/ITIL_Glossary_V3_1_24.pdf

[30] Organization for Security and Co-operation in Europe. (2012, June 20). www.osce.org. (Organization for Security and Co-operation in Europe) Retrieved June 20, 2012, from http://www.osce.org/who

[31] Pink Elephant \& BMC Software, Inc. (2007, Jun 18). Retrieved Avgust 2012, from http://www.pinkelephant.com

[32] Portal Kvalitet. (2012, Jul 8). Koristi od primene ISO/IEK 20000. Retrieved Jul 8, 2012, from http://www.kvalitet.org.rs/standardi/iso-iec-20000

[33] The Art of Service. (2012, June 16). http://theartofservice.com. Retrieved June 16, 2012, from http://theartofservice.com/creating-service-value.html

[34] The Stationery Office. (2007). The Official Introduction to the ITIL. London: The Stationery Office.

[35] Tucker, G. (2012, June 17). itsminfo.com. Retrieved June 17, 2012, from http://itsminfo.com/all-ireally-needed-to-know-about-titanics-deck-chairs-i-learned-from-itil/\#comments

[36] Universities and Colleges Information Systems Association. (2012, Jul 2). http://www.ucisa.ac.uk/. Retrieved Jul 2, 2012, from A Guide to Event Management: http://www.ucisa.ac.uk/ /media/Files/members/activities/ITIL/service_operation/eventm_managemen t/ITIL_a\%20guide\%20to\%20event\%20management\%20pdf

[37] Vlada republike Srbije. (2011, Jun 10). Službeni glasnik Info. (SIGlasnik) Retrieved Jun 10, 2012, from http://www.slglasnik.info: http://www.slglasnik.info/sr/53-20.07.2011/SI.-Glasnik/53/2011/

[38] Weekly, C. (2012, Avgust 13). www.computerweeklz.com. Retrieved 2012, from http://www.computerweekly.com/news/2240057336/Forrester-ITIL-boosts-efficiency 


\section{$1 / 1 / 1 / 1 / 1 / 1 / 1 / 1 / 1 / 1 / 1 / 1 / 1 / 1 / 1 / 1 /$ abouthe euthor}

Branislav Spasic

Organization for Security and Co-operation in Europe, Serbia

Branislav Spasic is an ICT assisstant in the Organiazion for European Security and Cooperation in Serbia. He completed his master studies at the Faculty of Organizational Sciences, University of Belgrade, in 2012. The main areas of his scientific interest are ICT management, ICT service financial management, information security management system (ISMS), operational service delivery systems, e-business, ITIL, computer networks, computer network safety.

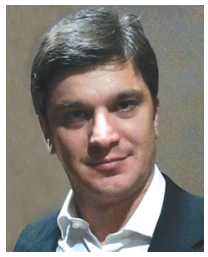

Aleksandar Markovic University of Belgrade, Faculty of organizational sciences aleksandar.markovic@fon.bg.ac.rs

Aleksandar Markovic is a Full Professor at the Faculty of Organizational Sciences, University of Belgrade, Serbia, where he got his MSc and PhD degrees in the field of Computer Simulation. Areas of his research include:e-business management, computer simulation, business simulation, business dyinamics. He is editor in chief of journal Management.

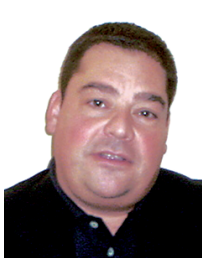

